\title{
A atuação das quitandeiras de Minas Gerais nas economias de mercado e de autoconsumo a partir de $1930^{1}$
}

\author{
Juliana Resende Bonomo*
}

\section{Introdução}

Desde os primórdios do povoamento de Minas Gerais, no início do século XVIII, uma variedade de elementos da pastelaria caseira esteve presente na alimentação diária dos habitantes da região mineradora. Ainda no século XXI, o hábito de consumo desse tipo de alimento permanece, permeado por tradiçóes do "saber fazer" e do servir as chamadas "quitandas", nome genérico utilizado para definir o conjunto da pastelaria caseira, do qual fazem parte bolos, broas, biscoitos, sequilhos, roscas, rosquinhas, pães de queijo, etc.

As mulheres que fazem e vendem quitandas, artesanalmente, são conhecidas como quitandeiras. A produção e a comercialização de quitandas é um ofício tipicamente feminino e praticado em cidades de pequeno e médio porte de Minas Gerais. As quitandeiras abordadas neste estudo exercem um trabalho domiciliar e por conta própria, em pequena escala e de forma artesanal. Entre elas, o "saber fazer” é marcado pelo conhecimento transmitido entre familiares, de geração em geração. De forma geral, as quitandeiras são mulheres de classe média, cuja renda líquida auferida é complementar à renda familiar; a posição social que ocupam

O presente artigo deriva da nossa dissertação de mestrado (BONOMO, 2014) e da nossa tese de doutorado (BONOMO, 2020).

Mestre em Memória Social pela Universidade Federal do Estado do Rio de Janeiro (UNIRIO) e Doutora em História Econômica pela Faculdade de Filosofia, Letras e Ciências Humanas (FFLCH) da Universidade de São Paulo (USP). E-mail: jujubonomo@gmail.com. 
nos municípios onde vivem permite-lhes formar uma rede de clientes, como uma pequena "reserva de mercado".

Devido a importância histórica e simbólica das práticas que envolvem a produção e o consumo de quitandas, o ofício das quitandeiras de Minas Gerais tornou-se objeto de políticas patrimoniais através do pedido de registro do ofício como patrimônio cultural imaterial junto ao Instituto de Patrimônio Histórico e Artístico Nacional (IPHAN). O pedido partiu de nossa própria iniciativa, com base em nossa dissertação de mestrado, juntamente com a Secretaria Municipal de Cultura de Congonhas, que vem a ser a proponente do pedido. A partir de nossa requisição, o IPHAN abriu o processo administrativo ${ }^{\circ}$ 01450.010688/201302. No ano de 2020, o processo encontra-se na fase de elaboração do inventário, que consiste em uma pesquisa de cunho etnográfico sobre as quitandeiras e suas práticas.

O presente artigo tem como objetivo analisar o ofício das quitandeiras no contexto da economia de autoconsumo, assim como no contexto da economia de mercado. A discussão proposta inicia-se na década de 1930, até a qual os depoimentos das nossas interlocutoras puderam retroceder no tempo. Enquanto trabalhadoras por conta própria, as quitandeiras ocupam os interstícios da economia de mercado, comercializando seus "artesanatos" através de pequenas transaçóes, trocas e encomendas por meio de tratos verbais entre parentes, vizinhos e afins. Tudo isso não está explícito em documentos ou nas estatísticas e, muito menos, na História oficial, pois se trata de relaçóes de troca baseadas na improvisação da subsistência do dia a dia, através de informaçóes compartilhadas entre pessoas conhecidas. Especialmente sobre a atuação de quitandeiras nos séculos XX e XXI, período abordado aqui, as informaçôes são ainda mais escassas.

Sendo assim, evidencia-se a importância da utilização da História Oral como uma metodologia capaz de obter informaçóes sobre um objeto de estudo cuja história apresenta muitas lacunas. Através da História Oral, foi possível apreender os sentidos e as interpretaçóes que as próprias quitandeiras têm de seu trabalho, algo que uma pesquisa quantitativa não poderia alcançar. Desse modo, este artigo busca contribuir para o conhecimento de uma parte importante da História Econômica e Social de Minas Gerais, ao mesmo tempo em que, através dos depoimentos coletados, contribui para a elaboração de documentos orais e escritos que podem vir a ser fontes de pesquisas futuras.

As entrevistas de campo foram realizadas nos anos de 2013 e 2018, nas seguintes cidades de Minas Gerais: Congonhas, Entre Rios de Minas, Jeceaba, Itaverava, São Brás do Suaçuí e Belo Horizonte - com exceção da capital, as demais cidades têm em comum o passado relacionado à mineração e à produção agropecuária. Em termos espaciais, essa pesquisa tem um escopo reduzido e 
não pretendemos generalizar as informações obtidas na pesquisa de campo para todo o estado. Neste artigo, foram utilizadas 18 entrevistas, realizadas com 17 pessoas, ${ }^{2}$ dentre elas, 13 quitandeiras, um quitandeiro, duas proprietárias de estabelecimentos comerciais e uma professora. Através das memórias das nossas entrevistadas, foi possível compreender as práticas das quitandeiras nas cidades pesquisadas a partir de 1930 até 2018, ano em que finalizamos a pesquisa de campo.

\section{A economia de autoconsumo e a sua relação com a produção de quitandas}

Em "Civilização material, economia e capitalismo: séculos XV-XVIII" (2009), a fim de compreender as questóes econômicas da sociedade europeia, Fernand Braudel desenvolveu uma espécie de "casa econômica" de três pisos. No andar térreo, encontra-se a vida material ou a "infra economia", a atividade da autossuficiência, da troca dos produtos e dos serviços em um raio muito curto. A vida material ou a civilização material envolve, principalmente, três campos: o meio ambiente das sociedades, as bases materiais do cotidiano (alimentação, vestuário, moradia) e as técnicas. Acima dela, no primeiro andar, está a economia de mercado, onde existem relaçóes de dois níveis: o primeiro, as "partículas elementares" - tendas de mascates, lojas e feiras - e o segundo, os "meios superiores, praças comerciais, bolsas ou grandes feiras". A partir deste último, imbricado no primeiro nível, desenvolve-se o que se chama de capitalismo, das grandes companhias até os monopólios. De modo similar, Ignácio Rangel (2012, p. 213), procurou compreender a economia brasileira como o resultado da combinação de três formações diferentes, superpostas tal como "as estruturas geológicas": o setor da "economia natural", o setor da "economia de mercado nacional" e o setor "resto do mundo", o qual engloba o mercado internacional. Como "economia natural", entende-se a produção para o consumo da própria unidade econômica produtora.

Nessa parte do trabalho, atentamo-nos ao que Braudel (2009) denominou de "nível térreo" ou "economia de autossuficiência" e que Rangel (2012) denominou de "economia natural". Por vezes, utilizamos também o termo "economia de autoconsumo" com o mesmo significado. Abordar o funcionamento do setor da

A quitandeira Raquel Ramalho contabiliza duas entrevistas, uma realizada em 2013 e outra realizada em 2018. Neste artigo, somente a entrevista de 2013 foi utilizada. 
economia natural é fundamental para a compreensão de duas questôes: a relação entre o cultivo de alimentos para o autoconsumo e a produção de quitandas; e o trabalho envolvido na produçáo de quitandas para o autoconsumo das famílias.

Seguindo a mesma tendência da arquitetura das casas urbanas e rurais dos séculos XVIII e XIX, os quintais ainda faziam parte de muitas casas das pequenas cidades mineiras até, pelo menos, a primeira metade do século XX. O número significativo de pessoas vivendo nas zonas rurais - $69,5 \%$ da população mineira em 1950, segundo o Censo Demográfico do IBGE (Instituto Brasileiro de Geografia e Estatística) - corroborado pelos depoimentos das nossas entrevistadas, levamnos a crer que havia famílias que se alimentavam daquilo que plantavam nos quintais de suas casas e, por isso, apenas eventualmente, recorriam ao comércio para adquirir alimentos. De acordo com os relatos, não só na zona rural, como até mesmo nos aglomerados urbanos, era possível encontrar o pequeno cultivo de alimentos nos quintais e nas hortas das casas. Nas roças ou nas pequenas cidades e vilas, a produção de quitandas dava-se a partir dos ingredientes disponíveis no próprio cultivo: frutas, ovos, leite, fubá, mandioca, etc.

Segundo a quitandeira Maria das Graças Dias (2018), nas décadas de 1940 e 1950, o seu pai cultivava alimentos para o autoconsumo para alimentar os filhos, que eram muitos, 12 no total. $\mathrm{Na}$ sua visão, como não havia benefícios previdenciários para os trabalhadores rurais, o pai teve que criar os filhos com o "trabalho braçal", querendo dizer que ele trabalhava na roça. Apesar do trabalho duro, ela gostava que o pai plantasse alimentos, pois, por causa disso, ela e os irmáos tiveram acesso a alimentos em abundância. Com o leite, o milho e a mandioca obtidos da fazenda, sua mãe fazia quitandas e doces.

Uma década depois, em 1960, as cidades da região pesquisada, com exceção de Belo Horizonte, ainda tinham características fortemente rurais, assim como o restante do estado de Minas Gerais, cuja população residente no campo representava $60 \%$ do total de habitantes do estado. ${ }^{3}$ Em muitos domicílios da região, ainda eram comuns as hortas e os quintais, onde se plantavam alimentos para o autoconsumo. A família da professora Kátia Souza, moradora da regiáo urbana de Congonhas, praticamente não comprava alimentos, pois tudo vinha do quintal de casa, desde as frutas e legumes, até o açúcar. Por esse motivo, para fazer as quitandas, quase não se compravam ingredientes.

Nós morávamos na cidade mesmo, mas tínhamos um quintal imenso. Tinha de tudo no nosso quintal. Para fazer as quitandas, a gente quase não

3 Censo Demográfico de 1960. Minas Gerais. Instituto Brasileiro de Geografia e Estatística (IBGE). Disponível em: <https://biblioteca.ibge.gov.br/visualizacao/periodicos/68/cd_1960_v1_t9_ mg.pdf $>$. Acesso em: 2 dez. 2020. 
comprava nada. O ovo, nós tínhamos em casa. Da cana, que nós tínhamos em casa, nós extraíamos a garapa para fazer o melado e o açúcar mascavo. $\mathrm{O}$ fubá, a gente fazia. A gente tinha todos os legumes e muita criação. (Kátia das Graças Souza, 2018).

Uma prática comum, na época, era a troca de alimentos entre os vizinhos. Quando sobravam alimentos - que "não tinham preço" - fazia-se a troca. A oferta de alimentos entre vizinhos, na realidade, era um sistema amplo de trocas sob a forma de presente, "um agrado". Segundo a nossa entrevistada Kátia, trocava-se de tudo: quitandas, legumes, frutas e doces. As trocas dependiam da sazonalidade dos alimentos e aquele que tinha algum alimento em abundância oferecia a quem não tinha. Aquele que ofertava algo não cobrava, mas, implicitamente, aguardava uma oferta equivalente. Quanto às quitandas e os doces, ofereciam-se os ingredientes, como ovos, leite, frutas ou as quitandas e os doces já prontos.

Dessa forma, de acordo com a ideia da "casa econômica" de Braudel, embora houvesse a troca de alimentos e quitandas entre os vizinhos, ainda se permanecia na "enorme massa de autoconsumo". Os agentes que as realizavam não chegavam a tocar o mercado, pois essa troca náo gerava um "pagamento" em bens ou dinheiro. Caso os agentes resolvessem vender parte dos excedentes, apenas para comprar uma ferramenta ou pagar impostos, eles tocariam somente a fronteira do mercado. No entanto, a partir do momento em que esses alimentos fossem vendidos para adquirir outros bens de consumo, os agentes passariam a fazer parte da economia de mercado (Braudel, 1987, p. 16). De acordo com os depoimentos, ainda hoje, em proporçóes menores, as trocas de alimentos entre vizinhos, como a descrita acima, persistem nas zonas rurais. Da mesma forma, ainda há quitandeiras que utilizam os ingredientes do próprio quintal para a produção de suas quitandas. Entretanto, de acordo a nossa pesquisa, a maioria das quitandeiras adquirem seus produtos de terceiros, sem necessariamente produzi-los.

A próxima questão a ser discutida em relação à "economia natural”, apontada por Rangel (2012), diz respeito a outro fator de produção: o trabalho. Para que se obtenha o produto final, no caso, a quitanda, é preciso que alguém a produza. A quitandeira que produz as quitandas para o autoconsumo da família tem duas opçóes: produzir as quitandas para suprir diretamente a necessidade do núcleo familiar ou exercer algum tipo de trabalho remunerado. Sua decisão assenta-se, pois, na comparaçáo de duas ordens de valores: a produçáo para o autoconsumo e a produçáo para o mercado. Com base na teoria de Rangel (2012), a quitandeira que produz para o consumo das famílias está "poupando" o salário familiar, pois ela está produzindo aquilo que poderia ser comprado fora da família, aumentando, de fato, a renda desta. 
Pode-se dizer, pois, que o produto da família é composto de duas partes: salário ganho mais "salário poupado". Os dois salários tornam-se contabilizáveis porque a família pode, em certas condiçóes, transferir parte dos fatores de que dispóe, da função de poupar para a de ganhar salário e vice-versa. Isso ocorre, por exemplo, quando a quitandeira deixa de produzir quitandas para a família e passa a exercer uma função remunerada (dentro ou fora do domicílio) e vice-versa. A partir do momento em que a quitandeira decide ganhar salário, ela irá comprar as quitandas em outro local, sendo que antes ela mesma produzia, à primeira vista, "gratuitamente". Em resumo, a quitandeira que produz quitandas para o autoconsumo está produzindo um valor que, normalmente, não é contabilizado, em termos monetários, pelas famílias. O mesmo acontece com outros tipos de trabalho doméstico.

Nas rememorações de algumas das nossas entrevistadas, o trabalho doméstico voltado para a própria família aparece com frequência. Utilizamos, de início, alguns depoimentos que remetem à década de 1930 para ilustrar essa questáo. Ao indagarmos sobre o passado das máes e avós das quitandeiras mais idosas, observamos que, no início do século XX, quando as famílias tinham um grande número de filhos, os serviços de casa eram divididos entre as filhas. Cada filha tinha uma obrigação, que poderia ser cuidar dos irmãos mais novos, costurar, lavar ou cozinhar. Nas primeiras décadas do século XX, não era comum às famílias de classe média da região pesquisada ter empregadas. Usualmente, as mulheres da família se encarregarem de todo o serviço da casa. Por esse motivo, nos depoimentos, a figura materna é sempre evocada pelo seu trabalho doméstico. A quitandeira Odete Silva descreveu sua mãe pelas suas habilidades nos serviços de casa, que tinha que "fazer de tudo", pois a família era grande e morava na zona rural.

Mamãe fazia quitanda somente para o gasto porque a família era muito grande. Ele tinha 11 filhos, então ela fazia somente para as despesas. Quando a gente morava na roça, a mamãe fazia de tudo. Doce, biscoito, costurava. Ela fazia só para casa, era uma família muito grande. (Odete Silva, 2013).

Stella Adelino, quando evocou as figuras da avó e da mãe, destacou a ajuda das filhas no trabalho de casa, onde cada uma tinha a sua tarefa. Como a obrigaçáo de sua mãe, na casa de sua avó, era tomar conta dos irmãos menores, ela não aprendeu a cozinhar. Assim que se casou, ela precisou aprender a cozinhar e a costurar, dois conhecimentos necessários às donas de casa das primeiras décadas do século XX.

Lá em casa, a minha mãe tinha filho de ano em ano. A minha mãe não teve empregada. Ela teve oito filhos, cinco mulheres e três homens, sendo quatro 
homens, um morreu muito pequeno. Lavar roupa, passar roupa, cozinhar, cada uma tinha a sua tarefa [...]. A minha avó também não teve empregada, lá também era a mesma coisa. (Stella Adelino, 2013).

Poucas décadas depois, em meados do século $\mathrm{XX}$, as rememorações da quitandeira Juraci, criada pela família para ser dona de casa, trouxeram à tona os valores da época, segundo os quais, a mulher tinha que servir ao homem, dando-lhe "tudo nas mãos". Quando ela disse ter aprendido a ser dona de casa, implicitamente, evidenciou-se o domínio de um conjunto de tarefas que fazem dela uma trabalhadora do lar.

A minha mãe teve cinco filhos. Ela fazia tudo sozinha. E ela criava a gente para cuidar da casa. Para ela, ser boa dona de casa era saber cozinhar, ter a casa sempre limpa e cuidar bem dos filhos e do marido. (Juraci Ferreira Barros, 2013).

No caso de famílias que tinham empregados, ainda assim, considerava-se importante o aprendizado das tarefas de casa pelos seus membros. Era a tese do "quem não sabe fazer, não sabe mandar", um ditado repetido pelas mães que desejavam que suas filhas fossem boas donas de casa. Caso contrário, a mulher seria mal vista pelo seu marido e pela sociedade, considerada pouco preparada para o comando do seu próprio lar, situação pela qual nenhuma mulher desejaria passar (Bassanezi, 1997). A mãe da quitandeira Odete Silva, por exemplo, fazia questão de ensinar as filhas a cozinhar e a costurar. Além de aprender para saber mandar, a mãe dela também acreditava em um tipo de "independência" no saber fazer, quando dizia: "se precisar fazer, sabe fazer."

Na divisão das tarefas de casa, a responsável por cozinhar aprendia a fazer todas as receitas que iam à mesa da família, inclusive as receitas de quitandas. Aprendiase, também, "por gosto", como as quitandeiras dizem, ou seja, pelo prazer de fazer. Estamos falando, então, de um trabalho que envolve um treinamento, um aprendizado e uma execução diária de tarefas. Mesmo assim, até na atualidade, o trabalho exercido no próprio domicílio, voltado para a família, não chega nem a ser visto como um trabalho. Talvez por não ser remunerado, talvez por ser exercido em casa. Por outro lado, embora não haja uma remuneração monetária, como nos fala Rangel (2012), a família "poupa salário" já que não paga outra pessoa para preparar as refeiçóes e as quitandas consumidas por seus membros.

Sobre a ligação das mulheres com os afazeres domésticos, no qual incluise a produçáo de quitandas para o autoconsumo, recorremos aos estudos da escritora Silvia Federici (2018) a fim de compreender as questóes históricas e sociológicas relacionadas à falta de visão dos afazeres do lar como um trabalho. 
Segundo essa autora (2018, p. 65), a configuração do trabalho doméstico, tal como a conhecemos, surgiu no final do século XIX e início do XX na Inglaterra e nos Estados Unidos, espalhando-se para o resto do mundo. A classe capitalista dos dois países, ao se ver pressionada pela rebeldia da classe operária e necessitada de uma mão-de-obra mais produtiva, empreendeu uma reforma nas relações de trabalho que transformou a fábrica, a comunidade, o local e, principalmente, a posição social das mulheres. A partir daí, o trabalho doméstico foi imposto às mulheres, sendo relacionado a um "atributo natural" de seus tipos físicos e personalidade, como se fosse uma aspiração decorrente do caráter feminino. Federici $(2018$, p. 68), então, se pergunta o quão natural é ser dona de casa, se são necessários anos de treinamento diário - dado por uma mãe não remunerada - para preparar uma mulher para esse papel.

No Brasil, a crescente industrialização a partir de 1930, ao tornar necessária a separação entre a casa e o trabalho, designou às mulheres as atividades caseiras. Segundo Singer e Madeira (1973, p. 5-7), a introdução da máquina veio reforçar a ideia de que cabe à mulher a administração do lar e a educação dos filhos. Desde o início do capitalismo, o trabalho doméstico, transformado em atributo natural e com a ausência de um "contrato social", estava destinado a ser "dispensado". Decorre disso a tentativa bem-sucedida do capital em convencer homens e mulheres de que se trata de uma atividade tipicamente feminina, natural, inevitável e gratificante, levando as donas de casa a compactuarem com a não-remuneração desse tipo de trabalho. Dessa forma, o trabalho doméstico aparece como "um serviço pessoal externo ao capital". Por seu lado, a condição não remunerada do trabalho doméstico acaba por reforçar a suposiçáo de que o trabalho doméstico não é trabalho.

Federici (2018), que nos anos 1970 coordenou uma campanha a favor de remuneração ao trabalho doméstico, afirma que, na ausência de salário, esse tipo de trabalho é tratado como um "ato de amor". Nas entrelinhas da afirmação "isso que chamam amor é trabalho náo pago", a autora chama a atenção para a apropriação do trabalho da mulher no âmbito familiar, onde se crê que, por amor, se limpa e se cozinha, ou seja, o amor é confundido com um serviço pessoal. ${ }^{4}$

Quanto ao trabalho das donas de casa voltado para o autoconsumo, é comum ouvirmos de maridos e filhos que suas esposas ou mães "não fazem nada" ou "não trabalham", ignorando a riqueza que é produzida pelo trabalho dessas mulheres para o funcionamento da casa e sobrevivência de seus membros. Esses

4 Silvia Federici fez uso dessa formulação em diversas entrevistas. Disponível em: < https://pcb.org.br/ portal2/13581/o-patriarcado-do-salario-o-que-chamam-de-amor-nos-chamamos-de-trabalho-naoremunerado/>. Acesso em: 3 dez. 2020. 
discursos reforçam, cada vez mais, a ideia de que esse tipo de trabalho é um "não trabalho" e, por isso, não precisa ser remunerado. Para o nosso objeto de estudo, é preciso lembrar que quitandeiras que produzem quitandas para o autoconsumo estão produzindo riqueza para a família ou, retomando Ignácio Rangel (2012), "poupando salário". Com isso, estão contribuindo para a produção e a reprodução da força de trabalho. Comumente, o conjunto de afazeres do trabalho doméstico é visto como um trabalho improdutivo, quando, na verdade, ele também produz riqueza na medida em que "a casa e a família também são um centro de produção" (Federici, 2018, p. 15). Porém, dificilmente, os membros da família e a sociedade têm essa visão. Em vez disso, os depoimentos das nossas entrevistadas deixaramnos a impressão de que havia uma "remuneração moral", como uma motivação para a boa execução das tarefas do lar: o título de "boa dona de casa".

No nosso objeto de pesquisa, o problema transcende a falta de visão dos afazeres domésticos como um "não trabalho" no ambiente familiar, impactando a própria visão que as quitandeiras têm de seu ofício quando produzem para o mercado. Por motivos que perpassam a discussão apresentada acima, a nossa pesquisa identificou uma dificuldade entre as próprias quitandeiras em se reconhecerem como trabalhadoras. Dentre as entrevistadas, a identificação com as tarefas do lar é tão forte, que nos surpreendeu o número de quitandeiras que não se identificam como tal quando perguntadas sobre sua profissão, declarando-se, somente, donas de casa. Por outro lado, as poucas entrevistadas que se declararam quitandeiras, como a Rose Mary Baeta, a Raquel Ramalho e a Maria das Graças, o fizeram com entonação de segurança e pleno reconhecimento de que fazer e vender quitandas é uma profissão.

Dentre as que se declararam donas de casa, a quitandeira Juraci Barros alega que não merece o título de quitandeira, porque acredita que tem muito o que aprender. Stella Adelino e Margarida Resende pensam que não podem ser chamadas de quitandeiras, porque não fazem quitandas todos os dias e não aceitam todas as encomendas que recebem. Há aquelas que se dizem donas de casa porque nunca trabalharam fora, como é o caso das quitandeiras Rosângela Freitas, Odete Silva e Leila Ribeiro, mesmo que a produção de quitandas ocupe uma parte considerável de seus cotidianos.

O depoimento da quitandeira Maria Isabel Rocha é um bom exemplo da não associaçáo do trabalho exercido em casa com uma atividade econômica. No seu relato, chamou-nos a atençáo quando ela declarou que depois de sentir a necessidade de ter uma renda, além daquela obtida com a venda das quitandas, ela, então, "começou a trabalhar". Em outras palavras, Isabel passou a se perceber como uma trabalhadora quando voltou a trabalhar fora do ambiente doméstico. 
Eu senti a necessidade de ter outra renda, porque só essa não dava. Aí eu comecei a trabalhar. Eu parei com as quitandas, porque, para mim, não estava compensando financeiramente. (Maria Isabel Rocha, 2018).

Apesar das justificativas das quitandeiras Juraci, Stella e Margarida revelarem aspectos da natureza artesanal e intermitente do trabalho, a nosso ver, os motivos para não se apropriarem da identidade de trabalhadoras passam, principalmente, por questóes econômicas e culturais. Mesmo exercendo tantas tarefas à parte daquelas do lar, o ambiente da casa parece estar no imaginário das quitandeiras como o lugar dedicado ao cuidado da família, sendo necessário "sair de casa para trabalhar". Além do trabalho realizado em casa, parece-nos que a renda intermitente e complementar à renda da família também dificulta a visão do ofício, pelas próprias quitandeiras, como uma profissão.

\section{As quitandeiras na economia de mercado}

Segundo Braudel (1987, p. 35), há duas formas da chamada "economia de mercado": a categoria "A", onde estão as trocas cotidianas do mercado, os tráficos locais ou à pouca distância e os comércios de maior raio de ação, quando são regulares, previsíveis, rotineiros e abertos tanto aos pequenos quanto aos grandes comerciantes; a categoria "B", onde estão os intermediários e os "atravessadores", as feiras e as Bolsas. Em suma, há o nível das trocas locais, onde a concorrência flui sem entraves, pela ausência de intermediários, ou seja, produtores e consumidores mantêm contato direto, como é o caso das quitandeiras pesquisadas. $\mathrm{O}$ outro nível, "superior", envolve a circulaçâo de mercadorias nacionais e internacionais, onde intermediários e mercadores itinerantes atuam como agentes econômicos; dentro deste conjunto está o capitalismo, entendido como a "esfera de circulaçáo".

A decisão da quitandeira de deixar de produzir quitandas apenas para o autoconsumo para produzir para o mercado traz uma série de implicaçóes que investigamos a seguir. Nesse contexto, procuramos priorizar a relação dessas trabalhadoras com o trabalho domiciliar e por conta própria. É importante deixar claro que a produção de quitandas para o autoconsumo e para o mercado sempre coexistiram e, por isso, não é possível falar de um período histórico em que tivesse ocorrido a transição de um tipo de produçáo para o outro. A decisão da quitandeira de produzir para o mercado é individual, podendo ocorrer em qualquer período histórico. A quitandeira é, pois, uma mulher que está com um "pé" na economia natural e o outro "pé" na economia de mercado".

Após a década de 30 do século passado, a estrutura de emprego no Brasil 
sofreu profundas transformaçóes em decorrência do processo de industrialização do país. Consequentemente, a participação da mulher na força de trabalho foi influenciada por essas modificaçôes. $\mathrm{O}$ aumento da especialização técnica, ao tornar necessária a separação entre casa e trabalho, veio a reforçar o papel da mulher na administraçáo do lar e o cuidado dos filhos. Juntamente com esse processo, foi acontecendo uma transferência da população ocupada em atividades agrícolas para outros setores da economia. De qualquer modo, fosse no campo, fosse na cidade, a mulher só trabalhava como "auxiliar do homem", no seio da própria família ou de uma família estranha (Singer; Madeira, 1973, p. 6).

Nos relatos que abordam até a década de 1950, essa constatação é facilmente identificada, pois demonstram o exercício de um trabalho relacionado a uma figura masculina, passível de ser conciliado com as tarefas domésticas. A avó da quitandeira Maria Teresa Silva, por exemplo, na década de 1940, fazia quitandas e sabão para vender no estabelecimento comercial do pai dela. Além de ganhar um "dinheirinho", ela trabalhava porque gostava de fazer quitandas. Na década de 1950, a avó, as tias e a mãe do quitandeiro Leopoldo Cordeiro faziam quitandas e doces para vender na padaria de seu pai. Leopoldo destaca que sua mãe seguiu trabalhando para ajudar o pai, mesmo enquanto estava grávida e com filhos pequenos para cuidar.

Embora os depoimentos corroborem a constatação de Singer e Madeira (1973), não podemos deixar de destacar as mulheres que, por diferentes motivos, assumiram a chefia da família, mesmo trabalhando no próprio espaço doméstico. Entre as nossas entrevistadas, dois depoimentos ilustram essa questão. A quitandeira Stella conta-nos que, na década de 1930, apesar de seu pai ser proprietário de uma padaria, era a mãe dela quem sustentava a casa vendendo quitandas. Com isso, ela criou os oito filhos praticamente sozinha.

A minha mãe trabalhava com comida, mas em casa. O meu pai tinha uma padaria e ela o ajudava. Ela fazia essas coisas para vender para ajudar a criar a gente. Ela criou a gente praticamente sozinha. $\mathrm{O}$ meu pai não tinha muita cabeça não. Ele trabalhava fora, ficava muito tempo fora de Entre Rios, demorava muito a vir em casa. Então, a mamãe trabalhava pra sustentar a gente porque eram oito filhos. (Stella Adelino, 2013).

Na década de 1950, a avó da chef Mariana Souza fazia doces, quitandas e salgados para vender, além de lavar e passar roupa para fora. Depois que o seu avô se acidentou, ele ficou impossibilitado de continuar praticando a sua profissão como domador de burros e cavalos. Por esse motivo, a sua avó assumiu a chefia da casa. 
A minha avó materna era doceira, quitandeira e lavadeira. Ela vivia disso. Meu avô, com oito meses de casamento, sofreu um acidente e ficou deficiente de uma perna. Ele era domador de burros e cavalos. Entấo, ele não conseguia mais trabalhar com isso. Por isso, era a minha avó que praticamente bancava a casa. (Mariana Cristina Oliveira Gontijo Souza, 2018).

Os depoimentos acima, portanto, têm como personagens mulheres que eram mães, trabalhadoras e chefes de família. Ressaltamos que domicílios chefiados por mulheres não sáo um fato novo do século XX e tampouco resultado da reestruturação dos costumes patriarcais. Trata-se, antes de tudo, de um fenômeno histórico, por vezes, fruto da ausência do principal provedor, da necessidade financeira ou de incidentes.

Todas essas questóes eram ainda mais marcantes nas áreas rurais e nas pequenas cidades abordadas nesse estudo. As mulheres, vistas como donas de casa e mães, ocupavam um espaço no imaginário social no qual predominava a ideia da incompatibilidade entre casamento e vida profissional. Entre as mulheres trabalhadoras, era comum interromper o trabalho por causa do casamento ou da chegada do primeiro filho (Bassanezi, 1997). Entre as nossas entrevistadas que se tornaram mães e esposas nas décadas de 1950/1960, percebe-se, claramente, como o casamento foi um impedimento para seguirem uma carreira profissional. A solução, então, para as que queriam trabalhar, foi exercer um tipo de trabalho domiciliar, como costurar e lavar "para fora" ou fazer quitandas e quitutes para vender.

A quitandeira Odete, que trabalhava como professora, deixou a profissão ao se casar, cedendo à pressão do marido. Depois disso, ela passou a trabalhar em casa, primeiramente como costureira e, depois, como quitandeira.

Quando eu era solteira eu dava aula, mas não era formada. Aí dei aula por quase sete anos, depois saí para me casar. Aí eu me casei e vieram os filhos. Quando eu me casei, eu boba, o Jaime (marido) não deixou eu dar aula mais. Eu desisti. (Odete Silva, 2013).

A quitandeira Maria Teresa deixou de trabalhar como auxiliar de escritório quando se casou e chegou a trabalhar temporariamente como quitandeira para complementar a renda quando ficou viúva.

Antes de me casar, eu trabalhei como auxiliar de serviço. Depois que me casei, parei de trabalhar. Eu cheguei a fazer bolos e outras quitandas para fora, quando eu fiquei viúva, em 1978, para melhorar minha renda. Eu fiz isso por uns três ou quatro anos. (Maria Teresa Oliveira de Miranda Silva, 2018). 
A partir da década de 1970, intensificou-se a entrada de mulheres no mercado de trabalho, em um contexto de expansão da economia, com acelerado processo de industrialização e urbanização. Os anos do chamado "milagre econômico" (1968-1973) impulsionaram a economia brasileira e o aumento da participação das mulheres no mercado de trabalho (Hoffmann; Leone, 2004). Os dados, todavia, mostram que em termos de mudanças de mentalidade não havia muito o que comemorar. Embora um crescimento da participação da mulher no mercado de trabalho tenha sido uma conquista importante na década de 1970, as atividades que mais abrigavam a mão de obra feminina demarcavam a segmentaçáo sexual no mercado de trabalho. Segundo Zylberstajn et al. (1985), as mulheres formavam verdadeiros "guetos ocupacionais" no mercado de trabalho, pois exerciam ocupaçóes menos valorizadas, tradicionalmente femininas e com menor remuneração, dentre as quais predominam as empregadas domésticas.

A década de 1980, ao contrário da anterior, teve como marca registrada a crise econômica, a inflaçấo e o desemprego. Não temos como comprovar, mas pensamos que a crise econômica pela qual o país passou naquele período foi, provavelmente, um dos motivos que impulsionou o ingresso de algumas quitandeiras na economia de mercado. Nesse contexto, elas se viram diante de uma situação na qual seria necessário produzir para o mercado a fim de complementar a renda familiar. Esse foi o caso das quitandeiras Stella - que começou a trabalhar quando os filhos entraram para o colégio e passaram a ter outras demandas - e Maria do Carmo Costa (2013), que começou a pagar o INPS $^{5}$ e, em um determinado momento, precisou de dinheiro para pagar uma cirurgia. Isso não significa, porém, que a questão financeira tenha sido a única responsável por mantê-las no mercado de trabalho. Passada a crise e com os filhos já independentes, Stella seguiu comercializando as quitandas, como o faz até hoje. Maria do Carmo não teve filhos, mas se acostumou a ter o seu próprio dinheiro e, por isso, segue exercendo o ofício de quitandeira.

Segundo nossa entrevistada Suleni Alves (2018), sua mãe, Dona Diva, é um exemplo de uma quitandeira que começou a trabalhar na década de 1980 por outra razão que não a necessidade financeira. Dona Diva sempre foi dona de casa e começou a trabalhar fora, aos 53 anos, por incentivo das filhas que pretendiam abrir uma lanchonete na Faculdade de Enfermagem da UFMG em Belo Horizonte.

$\mathrm{Na}$ década seguinte, de 1990, período caracterizado pela abertura econômica e pela crescente terceirização da economia, houve uma tendência

\footnotetext{
Instituto Nacional de Previdência Social.

6 Universidade Federal de Minas Gerais.
} 
de crescimento da incorporação da mulher na força de trabalho. No entanto, a inserção ocupacional das mulheres foi mais marcada por continuidades do que por mudanças. As ocupaçóes menos valorizadas e tipicamente femininas continuaram a se reproduzir, implicando na persistência de nichos ocupacionais, como o emprego doméstico (Hoffmann; Leone, 2004).

A partir do ano 2000, segundo dados da PNAD (Pesquisa Nacional por Amostra de Domicílios) analisados por Wajnman, (2006, p. 31), a inserção do contingente feminino, antes concentrado em emprego doméstico, trabalho autônomo e informal, evidenciou uma certa "conquista qualitativa". Em 2000, o total das mulheres trabalhadoras envolvidas em atividades domésticas reduziu e já se viam mais mulheres inseridas em cargos mais valorizados. A partir de 2003, as trabalhadoras passaram a constituir $43 \%$ da força de trabalho no Brasil, representando um "quase equilíbrio" na relação entre homens e mulheres. Nos anos seguintes, a tendência de crescimento da participação das mulheres na força de trabalho prosseguiu no país e, consequentemente, em Minas Gerais. A maior participaçáo das mulheres no mercado de trabalho é atribuída, principalmente, às mudanças demográficas, como a queda da taxa de fecundidade, o aumento da expectativa de vida, o aumento de domicílios uniparentais, o aumento da chefia feminina e o acréscimo da escolaridade feminina, que aumenta as recompensas "econômicas e não econômicas" associadas ao emprego (Bruschini, 2007; Camargos et al., 2014).

Diante dessas transformaçóes, no período entre 2000 e 2018, os motivos para iniciar e permanecer no ofício de quitandeira foram diversos, desde questóes financeiras, ao uso do trabalho como uma "atividade terapêutica", podendo também ter sofrido influência das mudanças demográficas apontadas acima. $\mathrm{Na}$ realidade, as motivaçóes superpóem-se, de forma que a quitandeira concilia uma forma de obter uma renda com outros benefícios. Nesse sentido, chamounos a atençáo a declaraçáo comum, ressaltada veementemente em todos os depoimentos: o prazer de realizar a atividade. Independentemente da principal motivação que leva uma pessoa a trabalhar com as quitandas, nas palavras das nossas entrevistadas, elas o fazem "com gosto" e "por gosto". Junto a isso, ter um dinheiro para si, uma autonomia financeira e uma certa independência do marido apareceram com frequência nos relatos. É preciso pontuar que trazer uma renda extra para a casa eleva a autoestima dessas mulheres, pois elas deixam de ser apenas aquelas que "poupam salário" para serem aquelas que também "ganham salário". 7 Outro elemento comum, implícito nos depoimentos, é a manutenção

Utilizamos a expressão "ganhar salário" no sentido figurado, pois, enquanto trabalhadoras por conta própria, as quitandeiras não recebem salário. 
do modelo tradicional familiar nas cidades pesquisadas, onde cabe à mulher as tarefas do lar e o cuidado dos filhos, sugerindo-nos ser o trabalho domiciliar a atividade ideal para essas trabalhadoras.

O relato da quitandeira Neiva Resende Chaves (2013) exemplifica essa questáo. Proibida pela mãe de estudar e de trabalhar, hoje casada, ela nos disse que, além do trabalho com as quitandas ser prazeroso, é possível conciliar com os cuidados dos filhos. Moradora da zona rural, é ela quem leva e busca os filhos no ponto do ônibus escolar. O seu marido não faz objeção à sua vontade de estudar, mas Neiva, aos seus 43 anos, sente-se "velha" para retomar os estudos. A produção de quitandas para o mercado iniciou-se por sugestáo da cunhada, que quis dividir com ela a sua clientela.

A quitandeira Rosângela, ao contrário de Neiva, não teve qualquer impedimento para estudar ou trabalhar, nem pelos pais, nem pelo marido. Antes de ser quitandeira, ela trabalhou como secretária, foi estagiária na mineradora Ferteco e trabalhou no escritório de advocacia do seu cunhado. A opção por parar de trabalhar fora veio após o nascimento do primeiro filho, que precisou de cuidados especiais por conta de um problema de saúde. Em seu depoimento, Rosângela fez questão de enfatizar que deixar o emprego foi uma decisão de comum acordo com o marido. A comercialização das quitandas foi incentivada pela sua primeira participação no Festival da Quitanda de Congonhas em 2007.

Eu nunca tinha pensado em trabalhar com quitanda, até que, em 2007, eu recebi um convite para participar do Festival da Quitanda. A partir daí, é que eu comecei a comercializar as quitandas. Eu náo tenho vontade de abrir um negócio, porque vai tirar o meu tempo para o cuidado da família e da casa. Eu gosto de estar dentro da minha casa, eu gosto de fazer as coisas aqui dentro. (Rosângela Rodrigues Freitas, 2018).

A quitandeira Raquel também trabalhou fora até se tornar mãe. Ela chegou a trabalhar com carteira assinada na General Motors (GM) e como ajudante de cozinha em um restaurante. Como é ela quem cuida dos filhos, ela mesma optou por trabalhar em casa.

Eu engravidei, não tive como voltar para a GM. Aí eu trabalho em casa, faço bolo de aniversário, docinho, de tudo um pouco. Parei quando vieram os filhos. São cinco filhos, eu que cuido deles. É Deus que ajuda a olhar, né? (Raquel Ramalho, 2013).

A quitandeira Leila, antes de comercializar as quitandas, nunca tinha realizado um trabalho remunerado. Mesmo assim, ela nos disse que trabalhava 
muito quando morava na roça, cuidando dos cultivos, da criação e dos filhos, mas nunca tinha uma remuneração, um dinheiro para si. O incentivo veio da cunhada que lhe sugeriu vender quitandas em sua loja. Leila, hoje, morando na cidade, faz as quitandas para ter um "dinheirinho" e "por gosto mesmo".

Quando eu morava na roça, eu nunca tinha um dinheirinho para mim. Aí quando eu comecei a vender biscoito, eu comecei a ter um dinheirinho na minha mão. Aí eu fui me empolgando e estou até hoje. Eu gosto de fazer, tenho prazer em fazer, eu faço por gosto mesmo. (Leila Maria Viana Ribeiro, 2018).

A conciliação dos cuidados com outros familiares, que não os filhos, igualmente, demandam a presença feminina em casa. A quitandeira Isabel Rocha, por exemplo, deixou o emprego no departamento financeiro de uma empresa em Belo Horizonte, mudou-se para a zona rural de Jeceaba e trabalhou como quitandeira para conciliar os cuidados com a mãe. Vanda Onésima Henriques (2018), quitandeira e produtora rural, trabalhava como cozinheira em um restaurante em Conselheiro Lafaiete. Há quatro anos, ela deixou o trabalho para cuidar do marido, hoje falecido, e do irmão acamado. $\mathrm{O}$ incentivo para comercializar as quitandas, que ela já produzia para o autoconsumo, veio das colegas da ASPRI (Associação dos Pequenos Produtores Rurais de Itaverava). Para Vanda, além do benefício da renda complementar, vender quitandas e doces é uma forma conveniente do aproveitamento de frutas, leite e ovos do próprio quintal.

A quitandeira Margarida começou a comercializar as suas quitandas na feirinha dos produtores rurais de Entre Rios no ano 2000. Com os filhos ainda pequenos, ela precisou assumir as despesas da casa quando o seu marido teve depressão. Logo, durante um tempo, Margarida assumiu a chefia da casa. Depois que o marido se recuperou, ele pediu para ela parar de trabalhar, mas Margarida alegou que a renda obtida do seu trabalho é importante para o orçamento familiar e que ela gosta de estar na feira pelo convívio com as outras pessoas.

Até aqui, então, evidenciam-se situações nas quais se destaca a divisão sexual do trabalho nas famílias das cidades pesquisadas. A mulher, no seu papel de mãe, cuidadora do lar e da família, acaba por optar em exercer um trabalho no ambiente doméstico para que possa conciliar com as tarefas de casa. Contudo, com exceção da quitandeira Odete, que deixou o emprego de professora quando se casou, e da quitandeira Neiva, cuja mãe não lhe permitiu nem estudar e nem trabalhar, as nossas entrevistadas não demonstraram arrepender-se de suas escolhas, tal como deixar um trabalho fora do ambiente doméstico para ser quitandeira. Afinal, elas exercem um ofício que lhes traz satisfação e trabalhar em casa é algo que 
fazem por vontade própria. Pela nossa observação, o cuidado com a casa e com os filhos faz parte dos valores dessas mulheres e, por isso, ao chamarem para si essa responsabilidade, elas medem os custos e os benefícios de exercerem um trabalho fora de casa. Pesam também características observáveis e não observáveis, relacionadas à posição social em que ocupam nesses municípios, ou seja, como membras de famílias de classe média em cidades com baixa urbanização, onde é possível criar uma rede de clientes e obter uma renda que é apenas complementar à renda da família.

Por ora, prosseguimos apontando outros incentivos para exercer o ofício de quitandeira surgidos nos depoimentos. No caso da quitandeira Rose Mary Baeta Neves (2018), a escolha de trabalhar com as quitandas, logo depois do casamento, deveu-se ao fato de ter ficado desempregada. O trabalho por conta própria, somado ao exercício de uma atividade que lhe proporciona prazer, foi a solução encontrada. Ela ainda afirmou de forma enfática que a renda adquirida com o seu trabalho significa a sua independência financeira.

Para o padeiro e quitandeiro Leopoldo Cordeiro, a profissão veio como uma continuidade natural dos negócios do pai. Além de vender suas quitandas na padaria, Leopoldo também vende na feira e na porta da escola. Quando perguntado sobre como era ser um homem quitandeiro, ele diz que considera como algo natural, que faz as quitandas porque gosta. Sua esposa Fifi, que trabalha com ele, destacou a importância desse trabalho no sustento da família e, por isso, diz que existem dois "lemas" na casa: 'transformar o trigo em pão' e outro, inspirado no trecho de uma música: 'tudo o que move é sagrado e o fruto do trabalho é mais que sagrado'. ${ }^{8}$

A quitandeira Odete, primeiramente exerceu um trabalho domiciliar como costureira. Com a morte da filha, ela quis mudar de atividade, dedicando-se à venda das quitandas. Aposentada como autônoma, a renda obtida com a venda das quitandas é importante, pois a aposentadoria não é suficiente para se manter. $\mathrm{Na}$ época da entrevista, em 2013, Odete tinha 72 anos. Apesar dos filhos e do marido insistirem para ela parar de trabalhar, por ser idosa, ela prefere continuar trabalhando, pois "não sabe ficar parada". Para Odete, o trabalho é também uma "terapia”, uma forma de distração, principalmente após a morte da sua filha.

A quitandeira Stella começou a trabalhar para ajudar a pagar as despesas do colégio dos filhos. Hoje, os filhos já crescidos pedem que ela pare de trabalhar. Atualmente com 80 anos, ela trabalha por opção, pois, nas suas palavras, "o trabalho é vida”. Maria das Graças, com 65 anos, em 2018, antes de ser quitandeira,

8 Trecho da música "Amor de índio", composta por Beto Guedes e Ronaldo Bastos. 
trabalhou na CPFL (Cia Paulista de Ferro Ligas) e no BEMGE (Banco do Estado de Minas Gerais), foi professora de Contabilidade e de Direito, provedora do hospital de Jeceaba, vereadora e presidente da Câmara. Depois de se aposentar, passou a ter mais tempo para se dedicar ao que realmente gosta de fazer: cozinhar. Assim como Odete e Stella, ela se recusa a parar de trabalhar porque "não quer ficar parada". Na sua opinião, a idade é um obstáculo para idosos conseguirem emprego. Vender quitandas foi o caminho encontrado para trabalhar com o que gosta e se manter ocupada, tal como ela deseja.

Para Maria das Graças, trabalhar com as quitandas tem vários significados, mas o que pesou na sua escolha foi o prazer de realizar a atividade. Maria das Graças, por fim, verbalizou uma questáo importante que perpassa o trabalho manual exercido pelas quitandeiras: o prazer de se produzir algo com as próprias mãos e o sentimento gratificante de levar satisfação aos clientes. Lembramos que o retorno pessoal dos clientes, a respeito da satisfação com as quitandas, só é possível nesses pequenos municípios, onde a comercialização é feita através de uma rede de clientes, já que não produzem em escala suficiente para atuarem nos mercados ou grandes lojas. Fazendo um paralelo com os estudos de Richard Sennett (2009, p. 21), podemos dizer que, ao ver um cliente satisfeito, Maria das Graças e as outras quitandeiras experimentam uma recompensa emocional típica do trabalho artesanal: o orgulho de suas "obras".

Nos depoimentos das quitandeiras Odete, Stellinha e Maria das Graças chamou-nos a atenção o desejo comum de permanecerem ativas na terceira idade. A necessidade de ocupar o tempo ocioso e a sensação de continuidade adicionam, ao prazer, elementos subjetivos importantes a serem considerados aqui. Junto a isso, a importância da complementação de renda à aposentadoria, por vezes, insuficiente para o autossustento. Estamos, portanto, tratando do trabalho de um grupo demográfico cada vez maior no Brasil: os idosos.

Em suma, podemos depreender do conjunto de depoimentos que os diferentes motivos para ser uma quitandeira, no período pós-2000, caminham juntos: o prazer de realizar o trabalho, a necessidade econômica, a complementação da renda familiar, a conveniência para conciliar com os cuidados da casa e o uso da atividade como forma de terapia/ocupação. É importante lembrar que, ao deixar de produzir para o autoconsumo e passar a produzir para o mercado, as quitandeiras também estão sujeitas à mesma dupla jornada das mulheres que trabalham fora de casa. Embora o fortalecimento das mulheres no mercado de trabalho venha provocando mudanças culturais, como a maior participação masculina nas tarefas do lar, entre as nossas entrevistas, ainda há uma superposição de atividades das mulheres.

Por fim, o conjunto de relatos demonstraram que o trabalho domiciliar e 
por conta própria são as principais características do ofício das quitandeiras que atuam nas cidades pesquisadas. Para esse grupo, consideramos o exercício de um trabalho domiciliar como consequência dos valores sociais que ainda impóem à mulher a administração da casa e o cuidado com os filhos. Podemos dizer que o trabalho exercido em casa é fruto da reunião de características observáveis como gênero, qualificação, número de filhos e o papel que a mulher exerce dentro de casa; e de características não observáveis, como a realização pessoal, o ciclo de vida, o histórico familiar e os valores pessoais. Para as trabalhadoras idosas, por sua vez, o trabalho por conta própria aparece como alternativa importante, já que não apresenta restriçóes de idade e o "saber fazer" é a condição mais importante para o ingresso e reconhecimento na economia de mercado.

\section{Referências}

BASSANEZI, Carla. Mulheres dos anos dourados. In: DEL PRIORI, Mary (Org.); BASSANEZI, Carla (Coord.) História das mulheres no Brasil. 2. ed. Sáo Paulo: Contexto, 1997. p. 607-639.

BONOMO, Juliana Resende. O que é que a quitandeira tem? Um estudo sobre a memória e a identidade das quitandeiras de Minas Gerais. Dissertação (Mestrado em Memória Social) - Unirio, Rio de Janeiro, RJ, 2014.

. "Com gosto" e "por gosto": o ofício das quitandeiras de Minas Gerais sob uma perspectiva histórica. Tese (Doutorado em História Econômica) - USP, São Paulo, SP, 2020.

BRAUDEL, Fernand. Civilização material, economia e capitalismo: séculos XV-XVIII. São Paulo: Martins Fontes, 2009.

. A dinâmica do capitalismo. Rio de Janeiro: Rocco, 1987.

BRUSCHINI, Maria Cristina Aranha. Trabalho e ge冈nero no Brasil nos últimos dez anos. Cadernos de Pesquisa, São Paulo, v. 37, n. 132, p. 537-572, set./dez. 2007.

CAMARGOS, Mirela Castro Santos et. al. Mercado de trabalho e gênero: uma análise das desigualdades em Minas Gerais. Revista Pretexto, Belo Horizonte, v. 15, n. 2, p. 41-57, abr./jun. 2014.

FEDERICI, Silvia. El patriarcado del salario: Críticas feministas al marxismo. Buenos Aires: Tinta Limón, 2018. 
HOFFMANN, Rodolfo; LEONE, Eugênia Troncoso. Participação da mulher no mercado de trabalho e desigualdade da renda domiciliar per capita no Brasil: 1981-2002. Nova Economia, Belo Horizonte, v. 14, n. 2, p. 35-58, mai./ago. 2009.

RANGEL, Ignácio. Obras reunidas. Rio de Janeiro: Contraponto, 2012. (v. 1).

SENNETT, Richard. The Craftsman. New Haven/London: Yale University Press, 2009.

SINGER, Paul; MADEIRA, Felicia. Estrutura do emprego e trabalho feminino no Brasil: 1920-1970. Caderno CEBRAP, São Paulo, n. 13, 1973.

WAJNMAN, Simone. Mulheres na sociedade e no mercado de trabalho brasileiro: avanços e entraves. In: PORTO, Marta (Org.). Olhares femininos, mulheres brasileiras. Rio de Janeiro: X Brasil, 2006. v. 4, p. 77-108.

ZYLBERSTAJN, Helio et al. A mulher e o menor na força de trabalho. São Paulo: Nobel, 1985.

\section{Fontes orais}

ADELINO, Stella [75 anos]. [jan. 2013]. Entrevistadora: Juliana Resende Bonomo. Entre Rios de Minas, MG, 26 jan. 2013.

ALVES, Suleni [55 anos]. [jul. 2018]. Entrevistadora: Juliana Resende Bonomo. Belo Horizonte, MG, 20 jul. 2018.

BARROS, Juraci Ferreira [63 anos]. [jul. 2013]. Entrevistadora: Juliana Resende Bonomo. Congonhas, MG, 7 jul. 2013.

CHAVES, Neiva Resende [40 anos]. [jan. 2013]. Entrevistadora: Juliana Resende Bonomo. Entre Rios de Minas, MG, 23 jan. 2013.

CORDEIRO, José Leopoldo (Leo) [55 anos]. [mai. 2018]. Entrevistadora: Juliana Resende Bonomo. Congonhas, MG, 22 mai. 2018.

COSTA, Maria do Carmo [77 anos]. [jan. 2013]. Entrevistadora: Juliana Resende Bonomo. São Brás do Suaçuí, MG, 24 jan. 2013.

DIAS, Maria das Graças [65 anos]. [mar. 2018]. Entrevistadora: Juliana Resende Bonomo. Jeceaba, MG, 9 mar. 2018. 
FREITAS, Rosângela Rodrigues [54 anos]. [mai. 2018]. Entrevistadora: Juliana Resende Bonomo. Congonhas, MG, 23 mai. 2018.

HENRIQUES, Vanda Onésima [58 anos]. [mar. 2018] Entrevistadora: Juliana Resende Bonomo. Zona rural de Itaverava, MG, 7 mar. 2018.

NEVES, Rose Mary Baeta [43 anos]. [mar. 2018] Entrevistadora: Juliana Resende Bonomo. Zona rural de Itaverava, MG, 7 mar. 2018.

RAMALHO, Raquel [41 anos]. [mai. 2013]. Entrevistadora: Juliana Resende Bonomo. Congonhas, MG, 22 mai. 2013.

RIBEIRO, Leila Maria Viana [42 anos]. [abr. 2018] Entrevistadora: Juliana Resende Bonomo. Entre Rios de Minas, MG, 12 abr. 2018.

ROCHA, Maria Isabel [52 anos]. [mar. 2018] Entrevistadora: Juliana Resende Bonomo. Jeceaba, MG. 9 mar. 2018.

SILVA, Maria Teresa Oliveira de Miranda [72 anos]. [mar. 2018] Entrevistadora: Juliana Resende Bonomo. Entre Rios de Minas, MG. 8 mar. 2018.

SILVA, Odete [75 anos]. [jan. 2013]. Entrevistadora: Juliana Resende Bonomo. São Brás do Suaçuí, MG, 24 jan. 2013.

SOUZA, Kátia das Graças [63 anos]. [mai. 2018]. Entrevistadora: Juliana Resende Bonomo. Congonhas, MG, 23 mai. 2018.

SOUZA, Mariana Cristina Oliveira Gontijo [34 anos]. [jul. 2018]. Entrevistadora: Juliana Resende Bonomo. Belo Horizonte, MG, 18 jul. 2018.

Resumo: Em Minas Gerais, a palavra quitanda é utilizada para designar o conjunto da pastelaria caseira, composto por bolos, biscoitos, broas, rosquinhas, etc. Quitandeiras são as mulheres que fazem e vendem quitandas artesanalmente. $\mathrm{O}$ ofício das quitandeiras, abordado neste estudo, caracteriza-se, principalmente, pelo trabalho por conta própria e domiciliar. No âmbito da História Econômica e da História Social, este artigo pretende compreender como acontece a produçáo de quitandas na economia de autoconsumo, assim como na economia de mercado. A metodologia utilizada foi a História Oral, tendo como arcabouço teórico os trabalhos de Fernand Braudel (1987, 2009), Ignácio Rangel (2012), Silvia Federici (2018), Paul Singer e Felicia Madeira (1973). As entrevistas de campo foram realizadas nos anos de 2013 e 2018, nas seguintes cidades mineiras: Congonhas, Entre Rios de Minas, Jeceaba, Itaverava, São Brás do Suaçuí e Belo Horizonte.

Palavras-chave: Quitandas. Quitandeiras. Minas Gerais. Trabalho por conta própria. Autoconsumo. Economia de mercado. 


\title{
The quitandeiras of Minas Gerais: how they perform in the market and self-consumption economies since 1930
}

\begin{abstract}
In Minas Gerais, the word "quitanda" is used to designate the set of homemade pastries, consisting of cakes, cookies, breads, donuts, etc. Quitandeiras are women who make and sell homemade pastries. The quitandeiras covered in this study is mainly characterized by self-employment and homework. In the context of Economic History and Social History, this article intends to understand how the quitandeira's production happens in the selfconsumption economy, as well as in the market economy. The chosen methodology was Oral History, with the theoretical framework of the following autohors: Fernand Braudel (1987, 2009), Ignácio Rangel (2012), Silvia Federici (2018), Paul Singer and Felicia Madeira (1973). Field interviews were conducted in the years 2013 and 2018, in the following cities in Minas Gerais: Congonhas, Entre Rios de Minas, Jeceaba, Itaverava, São Brás do Suaçuí and Belo Horizonte.
\end{abstract}

Keywords: Quitandas. Quitandeiras. Minas Gerais. Self-employment. Self-consumption. Market economy.

Recebido em 03/08/20

Aprovado em 31/10/20 